\title{
SIMBOL ZODIAK PADA MOTIF ORNAMEN KUMUDAWATI PURA MANGKUNENAGARAN
}

\author{
Arie Afriadi ${ }^{1}$, Dendi Pratama ${ }^{2)}$ \\ Program Studi Desain Komunikasi Visual, \\ Fakultas Bahasa dan Seni, Universitas Indraprasta PGRI \\ Jl. Nangka No. 58 C, Tanjung Barat, Jakarta 12530, Indonesia \\ arieafriadi54@gmail.com
}

\begin{abstract}
Abstrak
Simbol zodiak sudah dikenal di masyarakat sebagai dua belas simbol rasi bintang yang di tentukan pada hari, tanggal, dan bulan, simbol zodiak di ketahui berasal dari budaya barat yang masuk ke Indonesia dan lebih dikenal sebagai ramalan bintang. Namun terdapat tempat yang menjadikan simbol zodiak sebagai salah satu motif dalam hiasan bangunan, tempat itu adalah di Pendhapa Ageng Pura Mangkunegaran yang telah menjadikan simbol zodiak sebagai sebuah akulturasi kebudayaan antara kebudayaan barat dengan kebudayaan Jawa. Simbol zodiak tersebut termuat dalam sebuah hiasan langit-langit Pendhapa Ageng Pura Mangkunegaran yang diberi nama Motif Ornamen Kumudawati.
\end{abstract}

Kata Kunci: Zodiak, Motif Ornamen Kumudawati, Mangkunegaran.

\begin{abstract}
The zodiac symbol is known in the community as the twelve constellations specified in the day, date, and month, the zodiac symbol in the know comes from the Western culture that came into Indonesia and is better known as a horoscope. But there is a place that makes the zodiac symbol as one of the motifs in the building decoration, the place is in Pendhapa Ageng Pura Mangkunegaran that has made the zodiac symbol as an acculturation of culture between Western culture with Javanese culture. The symbol of the zodiac is contained in a ceiling ornament Pendhapa Ageng Pura Mangkunegaran which was named Ornament Motif Kumudawati
\end{abstract}

Keywords: Zodiac, Motive of Kumudawati Ornaments, Mangkunegaran

\section{PENDAHULUAN}

Simbol zodiak adalah sebuah kepercayaan yang muncul dari kebudayaan barat, yang berasal dari peradaban mesopotamia, berisi 12 simbol rasi bintang yang terdapat di langit dan terbagi menjadi beberapa nama sesuai posisi bintang yang sudah di tetapkan, nama-mana tersebut terdiri dari Aries, Taurus, Gemini, Cancer, Leo, Virgo, Scorpio, Sagitarius, Capricorn, Aquarius, dan Pisces. Di masa mesopotamia simbol zodiak di gunakan sebagai ilmu astronomi yang berfungsi sebagai informasi tentang nasib masa depan dan membantu dalam kehidupan sehari-hari seperti penentuan musim, menentukan arah mata angin, pergantian hari dan bulan karena pada masa itu perhitungan tentang terjadinya gerhana matahari dan bulan berdasarkan posisi bintang (Nasution 2018:109).

Di Indonesia terdapat simbol zodiak yang sudah beralkulturasi dengan kebudayan lokal Indonesia, yaitu kebudayaan Jawa. Simbol zodiak berisi tentang penamaan hari dan tahun sesuai kalender Jawa dan setiap simbol memiliki arti makna maknanya masing-masing. Simbol zodiak 
tersebut terdapat di dalam hiasan langit-langit Pendhapa Ageng Pura Mangkunegaran yang tergabung dalam beberapa motif dan diberi nama motif ornamen Kumudawati.

Pada saat ini motif ornamen Kumudawati masih menjadi daya tarik bagi masyarakat yang berkunjung pada Pura Mangkunegaran karena ukuran motif ornamen Kumudawati yang cukup besar dan letaknya pada langit-langit Pendapha Ageng, terlebih terdapat motif zodiak yang dimasukan ke dalam ajaran Jawa, hal ini tidak akan di temui pada tempat lain. Namun, kurangnya ketertarikan masyarakat dalam memahami makna simbolis yang terdapat dalam motif ornamen Kumudawati menjadikan motif ini hanya sebagai objek wisata dan kurangnya pengenalan dalam media visual sehingga kurang dikenalnya motif ornamen Kumudawati di luar kawasan Mangkunegaran.

\section{METODE PENELITIAN}

Metode penelitian ini menggunakan kualitatif, yaitu studi pustaka dengan pengumpulan data literatur dari jurnal artikel ilmiah, skripsi, dan buku. Pengumpulan data juga dilakukan dengan wawancara dengan salah satu narasumber, yaitu Ki Ngabehi Edy yang merupakan dalang sekaligus abdi dalem Pura Mangkunegaran, serta observasi langsung pada Pendhapa Ageng Pura Mangkunegaran Surakarta.

\section{HASIL DAN PEMBAHASAN}

\section{Motif hiasan langit pada Pendapha Ageng Pura Mangkunegaran}

Pendhapa Ageng Pura Mangkunegaran merupakan Pendhapa terbesar di Indonesia, Pendahapa ini dibangun pada awal pembangunan Pura Mangkunegaran, yaitu pada tahun 1815. Selanjutnya, pada tahun 1916-1944 Pendhapa Ageng dikembangkan oleh Mangkunegara ke-VII dengan menambahkan motif hiasan di beberapa bagian dengan mengambil beberapa unsur dari Eropa (Adisukma, 2014: 9). Yang paling penting dari penambahan pada Pendhapa Ageng Pura Mangkunegaran yaitu pada tahun 1937, Mangkunegara VII memberikan motif hiasan pada langitlangit Pendhapa Ageng Pura Mangkunegaran. Hiasan langit-langit itu di beri nama Kumudawati, berisikan beberapa motif simbolis dari beberapa pemahaman masyarakat Jawa yang magis serta relegius.

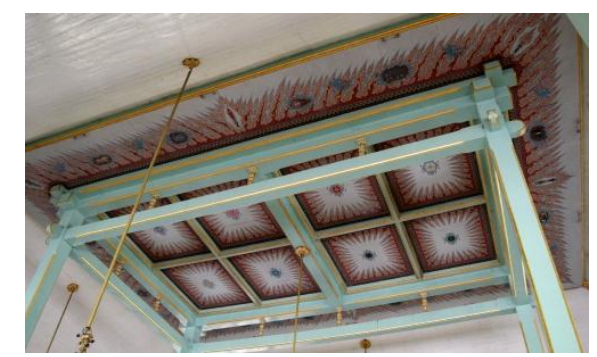

Gambar 1 Hiasan Kumudawati di Langit-langit Pendapa Ageng.

Sumber: Dokumen Pribadi

1. Motif Ornamen Kumudawati

Motif Ornamen Kumudawati merupakan sebuah motif hiasan yang diberikan pada langitlangit atau singup bangunan Pendhapa Ageng Pura Mangkunegaran yang di dalamnya terdapat berbagai motif hias, terutama motif Jawa, di antaranya lidah api atau modhang, tumpal, meru, atribut dewa mata angin, atribut hari dan tahun jawa, dan delapan warna magis. Seperti yang dikatakan Albiladiyah dalam wardanu bahwa Kumudawati merupakan hiasan singup. Singup pada Pendhapa Ageng merupakan suatu bidang segi empat yang terbentuk oleh empat saka guru, atau tiang utama, dihias dengan motif-motif yang secara keseluruhan dinamakan Kumudawati. Kata Kumudawati berarti bunga-bunga teratai putih. Di agama Hindu bunga teratai merupakan lambang kesucian dan dianggap sebagai tempat lahir dewa (Albiladiyah dalam Wardanu 2013: 66). 
2. Makna dan Arti dari Motif Ornamen Kumudawati

Kata Kumudawati berasal dari dua kata Kumuda dan Wati, Kumuda yang berarti teratai putih dan Wati berarti dunia, jagad, rahsa, cahaya atau sinar (Winter dalam Adisukma, 2014: 11). Selain dalam bentuk nama Kumudawati juga dapat tergambar dalam wujud ornamen Kumudawati, yaitu sebagai lambang kesucian dengan bidang persegi yang berjumlah delapan buah yang membentuk teratai yang dipercaya sebagai lambang kesucian dalam agama Hindu dan berkaitan dengan tempat keberadaan para dewa (Van der Hoop dalam Adikusuma, 2014: $11)$.

Warna putih teratai juga muncul sebagai background warna ornamen Kumudawati. Hal itu mengungkapkan bahwa Kumudawati memiliki makna sebagai dunia para dewa atau cara pendekatan diri melalui rahsa kepada Tuhan, ataupun cahaya ketuhanan yang menyikapi ajaran ketuhanan dalam sebuah ornamen. Melalui ajaran yang terdapat dalam ornamen Kumudawati, manusia Jawa diajarkan bagaimana cara mendekatkan diri kepada Tuhan dalam menjalani hidup di dunia, agar manusia selalu mendapatkan cahaya ilahi (hidayah) dan selalu dalam keadaan "suci" (Adisukma, 2014: 12). Jadi, makna ornamen keseluruhan mengajarkan manusia untuk menguasai dirinya dan bagaimana caranya agar manusia senantiasa mendekatkan diri kepada Tuhan Yang Maha Esa dengan cara menyucikan diri dari sifat-sifat kotor yang manusia dapat perbuat.

3. Mangkunegara VII Mengembalikan Budaya Tradisional Jawa ke Era Modern

Pada saat Mangkunegara ke-VII bertakhta, tahun 1916, turut melakukan pengembangan pada Pura Mangkunegaran yang memberikan nuansa Eropa, tetapi tidak menghilangkan budaya Jawa itu sendiri. Salah satu hal yang dilakukan adalah menambahkan motif hiasan pada langit-langit Pendhapa Ageng Pura Mangkunegaran. Inilah yang dilakukan oleh Mangkunegara VII dalam karya budayanya, yaitu menghidupkan kembali budaya Jawa dengan mengharmonisasikan budaya Barat yang terlanjur berkembang di Surakarta.

Atas dasar itu, tidak mengherankan apabila Mangkunegara VII ingin mewujudkan kembali keagungan budaya masa lampau dalam kemasan masa kini, sebagai upaya untuk memapankan kembali kebudayaan Jawa. Salah satu karya budaya Jawa kuna yang dihadirkan kembali dalam kemasan masa kini adalah motif ornamen Kumudawati yang terdapat pada singup Pendhapa Ageng Pura Mangkunegaran (Adisukma, 2014: 11)

Pembuatan Motif ornamen Kumudawati dilatarbelakangi oleh rasa ingin mengembalikan kebudayaan Jawa yang sangat agung dengan menambahkan nuansa modern, tetapi tidak meninggalkan budaya klasik khas Jawa itu sendiri. Hal ini yang dapat disimbolkan ke dalam pembuatan motif Kumudawati yang berisi simbol zodiak yang berasal dari barat juga sebagai hasil dari pemikiran mangkunegara ke VII yang modern, tetapi tetap memegang teguh budaya lokal sebagai orang Jawa.

Seperti yang disampaikan oleh Ki ngabehi Edy bahwa "Seluruh Bangunan pura Mangkunegaran yang mempunyai nuansa Eropa adalah hasil dari pemikiran Mangkunegara VII yang saat itu sering berhubungan dengan orang-orang barat" (Wawancara dengan Bapak Ki Demang Edy, 28 Mei 2018).

\section{Motif Zodiak pada Motif Ornamen Kumudawati}

Motif zodiak yang terdapat dalam Ornamen Kumudawati terletak di luar motif delapan warna magis dan menghampit motif atribut Dewa Mata Angin. Motif ini berisi atribut hari dan tahun dalam kalender Jawa berupa simbol zodiak yang telah di sesuaikan ke dalam ajaran Jawa.

Dalam pemaknaan pada watak hari pasaran, adalah penggambaran watak manusia dilihat dari hari pasaran atau pitungan Jawa, yaitu Legi, Paing, Pon, Wage, Kliwon yang masing - masing gambar mempunyai maksud yang berbeda-beda. Sistem perhitungan hari yang bersiklus lima (panca warna atau dina lima) itu umum disebut pasaran, pemaknaan dari berbagai macam gambar yang dihubungkan dengan dewa atau dewi menurut hari pasaran. Makna simbolisnya memiliki watak, karakter atau sifat manusia yang berbeda-beda satu sama lain berdasarkan dewa atau dewi 
penganut hari-hari pasaran tertentu. Kesemuanya berisi tentang larangan dan tuntunan, sedangkan Watak tahunan berisikan tentang watak yang dihitung dari tahun Jawa pada hari pertama bulan Sura awal Tahun Baru Jawa. Digambarkan dengan hewan yang masing-masing menyimbolkan awal tahun baru yang jatuh pada hari-hari tertentu arti simbolisnya berhubungan dengan kejadian alam (Sunarman, 2010: 201-202).

Di bawah ini adalah gambaran dari watak hari dan tahun pasaran Jawa berupa simbol zodiak berikut makna yang terkandung di dalamnya.

1. Watak Hari Pasaran

\begin{tabular}{|c|c|c|c|}
\hline 1. & & $\begin{array}{l}\text { Jemparing/ } \\
\text { Gandewa } \\
\text { (Sagitarius) }\end{array}$ & $\begin{array}{l}\text { Simbol dari hari Pon, perwakilan Sang Hyang } \\
\text { Brahma, bersifat suka menunjukkan kekayaan } \\
\text { angkuh dan sombong serta hanya memikirkan } \\
\text { hal dunia, sifat ini harus dihindari oleh manusia } \\
\text { karena di dunia kita hanya sementara apalah art } \\
\text { harta dunia karena tidak akan dibawa mati. }\end{array}$ \\
\hline 2. & & Leo & $\begin{array}{l}\text { Simbol dari hari Pahing, perwakilan dari Sang } \\
\text { Hyang Kala, bersifat ingin memiliki segala hal, } \\
\text { maknanya janganlah menjadi orang yang ingin } \\
\text { memiliki sesuatu yang bukan menjadi haknya. }\end{array}$ \\
\hline 3. & & $\begin{array}{l}\text { Jambangan } \\
\text { (Aquarius) }\end{array}$ & $\begin{array}{l}\text { Simbol dari hari pasaran Wage, perwakilan dar } \\
\text { Dewa Wisnu, bersifat berpendirian tegas, tepa } \\
\text { dalam berbicara, berhati keras dan sukar } \\
\text { diperintah, maknanya sebagai manusia } \\
\text { dianjurkan memiliki pendirian dalam sikap } \\
\text { tetapi tidak boleh egois dan harus mengharga } \\
\text { pendapat orang lain agar dapat disegani. }\end{array}$ \\
\hline 4. & & Traju (Libra) & $\begin{array}{l}\text { Simbolis dari hari pasaran Kliwon, dengan } \\
\text { perwakilan dari Sang Hyang Guru, bersifa } \\
\text { pandai bicara dan menguntai kata sehingga } \\
\text { menarik perhatian, makna simbolisnya adalah } \\
\text { dalam kehidupan bermasyarakat hal tersebu } \\
\text { perlu dicontoh, karena sifat supel akan banyak } \\
\text { mendatangkan teman dan tentu saja akan sangat } \\
\text { disukai oleh orang lain. }\end{array}$ \\
\hline 5. & & Wanita (Virgo) & $\begin{array}{l}\text { Simbol dari hari pasaran Legi, perwakilan dar } \\
\text { Dewi Sri, bersifat menolak semua pekerjaan } \\
\text { maknanya adalah ringan tangan dan saling } \\
\text { tolong menolong dan menyimbolkan wanita } \\
\text { sebagai penerus kehidupan. }\end{array}$ \\
\hline
\end{tabular}


2. Watak Tahunan

\begin{tabular}{|c|c|c|c|}
\hline 1. & & $\begin{array}{l}\text { Mahendra } \\
\text { (aries) }\end{array}$ & $\begin{array}{l}\text { Lambang awal tahun Jawa yang jatuh pada Setu } \\
\text { atau tumpak, karena itu, tahun itu sering disebut } \\
\text { dengan tahun Tumpak-mahendra. Sifat tahun } \\
\text { tumpak mahendra adalah terang, tidak ada } \\
\text { hujan }\end{array}$ \\
\hline 2. & & $\begin{array}{l}\text { Banteng } \\
\text { (Taurus) }\end{array}$ & $\begin{array}{l}\text { Lambang awal tahun yang jatuh hari Rebo, } \\
\text { Buddha atau Buda, awal tahun yang jatuh pada } \\
\text { hari Buda dengan simbol mahisa disebut Buda- } \\
\text { mahisa yang menunjukkan watak dan sifat } \\
\text { tahun yang banyak hujan }\end{array}$ \\
\hline 3. & & $\begin{array}{l}\text { Ketonggeng } \\
\text { (scorpio) }\end{array}$ & $\begin{array}{l}\text { Lambang awal tahun Jawa yang jatuh pada hari } \\
\text { Akad atau dite, yang berarti memengaruhi } \\
\text { turunnya hujan. Sifat tahun ini berpengaruh } \\
\text { pada musim yang panas. Dengan demikian, } \\
\text { frekuensi hujan berkurang. }\end{array}$ \\
\hline 4. & & $\begin{array}{l}\text { Mimi mintuna } \\
\text { (Gemini) }\end{array}$ & $\begin{array}{l}\text { Lambang awal tahun Jawa yang jatuh pada hari } \\
\text { Kemis atau Respati, karena itu, awal tahun } \\
\text { Kemis mintuna biasanya disebut dengan } \\
\text { respati-mintuna. Awal tahun yang ditandai } \\
\text { dengan simbol respati-mintuna merupakan } \\
\text { tahun yang banyak curah hujan yang disertai } \\
\text { dengan angin. }\end{array}$ \\
\hline 5. & & Ulam (Pisces) & $\begin{array}{l}\text { Simbol awal tahun Jawa yang jatuh pada hari } \\
\text { Senin atau Soma, awal tahun baru pada hari } \\
\text { Soma yang diberi simbol wecit dinamakan } \\
\text { Soma wecita. Sifat tahun yang mempunyai } \\
\text { lambang demikian biasanya menandakan } \\
\text { panjangnya musim hujan di sepanjang tahun } \\
\text { bagai hujan rintik-rintik. }\end{array}$ \\
\hline 6. & & $\begin{array}{l}\text { Yuyu, } \\
\text { (capicorn) }\end{array}$ & $\begin{array}{l}\text { Simbol awal tahun Jawa yang jatuh pada hari } \\
\text { Selasa atau Anggara, awal tahun yang jatuh } \\
\text { pada hari Anggara dengan lambang rekatha } \\
\text { disebut Anggara-Rekatha. Sifat tahun yang } \\
\text { demikian biasanya hujan terus menerus tiap } \\
\text { hari. }\end{array}$ \\
\hline 7. & & Urang (cancer) & $\begin{array}{l}\text { Simbol awal tahun yang jatuh pada hari Jemuah } \\
\text { atau Sukra, itulah sebabnya tahun ini lebih } \\
\text { dikenal sebagai taun Sukra-Mangkara. Sifat } \\
\text { tahun ini adalah hujan yang tidak merata, antara } \\
\text { satu tempat dengan tempat lainnya tidak sama. }\end{array}$ \\
\hline
\end{tabular}




\section{SIMPULAN}

Simbol zodiak yang terdapat di dalam Motif Ornamen Kumudawati merupakan sebuah akulturasi sebuah budaya modern Barat dengan budaya tradisional Jawa. Hal ini adalah hasil dari sebuah pemikiran dari seseorang Mangkunegara VII yang memiliki tujuan untuk mengembalikan kebudayaan tradisional disaat kebudayan asing telah berkembang pesat. Selain itu, tujuan di masukannya motif zodiak pada hiasan langit Motif Ornamen Kumudawati adalah sebagai landasan dan pelajaran kepada manusia dalam bersikap dan untuk menjalani kehidupan di dunia dengan sebaik-baiknya.

\section{DAFTAR PUSTAKA}

Adisukma, W. (2016). Makna ornamen Kumudawati Pendhapa Ageng Mangkunegaran. Acintya Jurnal Penelitian Seni Budaya, 6(1), 8-13.

Nasution, M. F. M. (2018). Perkembangan Ilmu Falak Pada Peradaban Pra Islam. Jurnal Penelitian Medan Agama, 9(1), 141-156.

Sunarman, Y. S. (2010, Febuari). Bentuk rupa dan makna simbolis ragam hias di Pura Mangkunegaran Surakarta. Fakultas Sastra dan Seni Rupa, Universitas Sebelas Maret, Surakarta.

Wardanu, D. P. (2013). anaslisis visual ragam hias Kumudawati pada langit langit Pendhapa Ageng Pura Mangkunegaran Surakarta. Program Studi Pendidikan Seni Rupa, Fakultas Keguruan dan Ilmu Pendidikan, Universitas Sebelas Maret, Surakarta. 